\title{
The Regener-Pfotzer Maximum during a Total Solar Eclipse
}

\author{
Gordon McIntosh ${ }^{1}$ \\ University of Minnesota, Morris, Morris, Minnesota 56267 \\ Alaina Swanson ${ }^{2}$, Liam Taylor ${ }^{2}$ \\ University of Minnesota, Morris, Morris, Minnesota 56267 \\ Erick Agrimson ${ }^{3}$, Kaye Smith $^{4}$ \\ Saint Catherine University, Saint Paul, Minnesota 55105 \\ and \\ Alynie Xiong 5 \\ Saint Catherine University, Saint Paul, Minnesota 55105
}

\begin{abstract}
The Regener-Pfotzer (RP) maximum is the altitude at which cosmic radiation intensity is the greatest. A decrease of the altitude of the interaction layer, assumed to be measured by the RP maximum, has been suggested to account for a reduction in the secondary cosmic ray flux measured at the surface of the Earth during a total solar eclipse. To investigate this suggestion, high altitude cosmic radiation was measured using Geiger Mueller (GM) counters carried beneath weather balloons both before and during the total solar eclipse on 21 August 2017. The 19 and 20 August 2017 omnidirectional RP maxima occurred at an average altitude of $20.2 \mathrm{~km} \pm 0.9 \mathrm{~km}$. During the eclipse of 21 August 2017 the omnidirectional RP maxima occurred at an altitude of $20.4 \mathrm{~km} \pm 0.8 \mathrm{~km}$. The 19 and 20 August 2017 vertical coincidence RP maxima occurred at an altitude of $18.3 \mathrm{~km} \pm 1.0 \mathrm{~km}$. During the eclipse the vertical coincidence RP maxima occurred at $18.0 \mathrm{~km} \pm 1.0 \mathrm{~km}$. Our results do not show any decrease in the altitude of either the omnidirectional or the vertical coincidence RP maximum outside the range of our measurements before the eclipse.
\end{abstract}

\section{Nomenclature}

$\begin{array}{ll}G M & =\text { Geiger Mueller counter } \\ G P S & =\text { Global Positioning System } \\ R P & =\text { Regener- Pfotzer maximum } \\ C D T & =\text { Central Daylight Time }\end{array}$

\section{Introduction}

$\mathrm{C}$ osmic rays, mostly high energy protons, continuously impinge on the Earth from all directions in space. Many of these primary cosmic rays originate in distant sources, possibly supernova remnants. There are cosmic rays generated by the Sun, but since the Sun had a low level of activity [1] during the time of our observations (19, 20, and 21 August 2017), solar cosmic rays had only a small contribution to our results. The primary cosmic rays

\footnotetext{
${ }^{1}$ Professor of Physics, University of Minnesota, Morris, 600 East $4^{\text {th }}$ St, Morris, MN 56267.

${ }^{2}$ Undergraduate Student, University of Minnesota, Morris, 600 East $4^{\text {th }}$ St, Morris, MN 56267

${ }^{3}$ Associate Professor of Physics, Saint Catherine University, 2004 Randolph Avenue, \#4105, St. Paul, MN 55105.

${ }^{4}$ Assistant Professor of Physics, Saint Catherine University, 2004 Randolph Avenue, St. Paul, MN 55105.

${ }^{5}$ Undergraduate Student, Saint Catherine University, 2004 Randolph Avenue, St. Paul, MN 55105.
} 
interact with atmospheric atoms or molecules and produce a shower of secondary particles in the general direction of the momentum of the primary.

The secondary particles include ionizing particles, pions, muons, electrons, positrons, and photons, that undergo decays and energy loss through interactions as they travel through the atmosphere. So a changing profile of particles and energies is generated in the atmosphere. This profile has a maximum intensity at the RP maximum [2]. The RP maximum is generally measured to be at an altitude of approximately $21 \mathrm{~km}$. However the omnidirectional intensity maximum and the maximum of vertical coincidence intensity do not occur at the same altitude. Our high altitude balloon based measurements allow us to investigate the cosmic ray intensity profile up to an altitude of approximately $33 \mathrm{~km}$.

It has been well documented that meteorological changes in the main interaction layer affect the overall intensity of secondary cosmic rays throughout the atmosphere and at the surface of the Earth. Models of these effects have been presented by Allkofer [3] and Pomerantz [4]. The main interaction layer occurs at a pressure of about 10,000 $\mathrm{Pa}$ at an altitude of about $16000 \mathrm{~m}$. If the pressure in this layer increases, the surface intensity drops by $\sim 0.2 \%$ per $100 \mathrm{~Pa}$. A temperature increase of $1^{\circ} \mathrm{C}$ in this layer, increases the surface intensity by $\sim 0.1 \%$. A change in the height of the main production layer of $1 \mathrm{~km}$ decreases the surface intensity by $\sim 5 \%$. A number of researchers, Berkova [5], Savic [6], and De Mendonca [7], have recently used these models to interpret the results of their measurements. A detailed analysis of meteorological effects on high energy and low energy muons has been presented by Dorman [8].

Due to the physics of pion decays and interactions and muon decays there is an angular dependence to the secondary cosmic ray intensity. (Pions interact through the nuclear strong, nuclear weak force and the electromagnetic force. Muons interact through the nuclear weak force and the electromagnetic force.) Pions, $\pi^{ \pm}$, are produced in the initial primary cosmic ray interaction and have a half-life of $2.6 \times 10^{-8} \mathrm{~s}$. Muons, $\mu^{ \pm}$, are produced through the decay of charged pions, $\pi^{ \pm}$,

$$
\pi^{ \pm} \rightarrow \mu^{ \pm}+v_{\mu}\left(\overline{v_{\mu}}\right)
$$

where $v_{\mu}$ and $\overline{v_{\mu}}$ represent muon neutrinos and muon anti-neutrinos. Muons have a half-life of $2.2 \times 10^{-6} \mathrm{~s}$ and decay by

$$
\mu^{ \pm} \rightarrow e^{ \pm}+v_{e}\left(\overline{v_{e}}\right)+\overline{v_{\mu}}\left(v_{\mu}\right)
$$

where $\mathrm{e}^{ \pm}$represents electrons and positrons and $v_{\mathrm{e}}$ and $\overline{v_{e}}$ represent electron neutrinos and electron anti-neutrinos.

Time dilation allows highly relativistic muons to reach the surface of the Earth. At the surface of the Earth muons make up over $99 \%$ of the cosmic ray intensity [9]. For the strongly interacting pions, as the zenith angle increases the mass per unit area increases, more strong force interactions occur, and fewer muon producing decays are likely. For a fixed path length, higher mass per unit area layers are reached more quickly for nearly vertical pion trajectories generating more interactions in that direction. So the pion mean free path depends on the zenith angle. These pion and muon decays and interactions produce a surface muon intensity that is proportional to the nth power of the cosine of the zenith angle. The value of $n$ depends on the energy of the muons, but it is close to 2 for integrated intensities [9]. The angular variation of cosmic ray intensity as a function of altitude has been observed $[10,11]$ but has not been well studied. Quantitative theoretical models of the altitude dependence of the zenith angle variation of cosmic ray intensity with which to compare our results have not yet been developed.

Various researchers have measured changes in the neutron, $\gamma$ ray, X-ray, and charged particle fluxes at the surface of the Earth during eclipses [12-19]. Several theories have been put forward to explain the observed variations. Bhattacharya et al. [12] suggested that the cooling of the atmosphere that occurs during a solar eclipse results in a decrease in the altitude of the interaction layer. This decrease in altitude leads to a reduction of the cosmic ray flux measured at the surface. Kandemir et al. [14] observed a decrease in the cosmic ray intensity that corresponded in time to slightly before the maximum of a partial solar eclipse. An increase just prior to an eclipse followed by a decrease during the eclipse has also been reported [15]. Chintalapudi et al. [13] and Devendra et al.[19] concluded that the reduction of the $\gamma$ rays and X-rays measured during total and partial solar eclipses was due to the Moon directly blocking the radiation from the Sun. Several authors $[15,18]$ have concluded that the physical causes of the changes in the cosmic ray flux have not been determined.

\section{Equipment}

In order to study the effects of the total solar eclipse of 21 August 2017 on the cosmic ray intensity as a function of altitude, groups from St. Catherine University and the University of Minnesota, Morris launched seven stratospheric 
balloon flights from central Nebraska on 19, 20, and 21 August, 2017. The flights, numbered one through seven, with the launch date and time and other flight information, are presented in Table 1 and Table 2.

\begin{tabular}{|c|c|c|c|c|c|c|c|}
\hline $\begin{array}{l}\text { Flight } \\
\text { Number } \\
\text { (System) }\end{array}$ & $\begin{array}{l}\text { Date } \\
\text { (Launch } \\
\text { time } \\
\text { CDT) }\end{array}$ & $\begin{array}{l}\text { Launch } \\
\text { Site }\end{array}$ & $\begin{array}{l}\text { Omnidirectional } \\
\mathrm{RP} \text { maximum } \\
(\mathrm{km})\end{array}$ & $\begin{array}{l}\text { Vertical } \\
\text { Coincidence } \\
\text { RP Maximum } \\
(\mathrm{km})\end{array}$ & $\begin{array}{l}\text { Burst } \\
\text { Altitude } \\
(\mathrm{km})\end{array}$ & $\begin{array}{l}\text { Time at } \\
\text { Burst } \\
\text { (CDT) }\end{array}$ & $\begin{array}{l}\text { Recovery } \\
\text { Site }\end{array}$ \\
\hline $\begin{array}{l}1 \\
\text { (Stratostar) }\end{array}$ & $\begin{array}{l}\text { 19 Aug } \\
(11: 45)\end{array}$ & $\begin{array}{l}\text { Grand } \\
\text { Island, } \\
\text { NE }\end{array}$ & $20.6 \pm 1.2$ & $18.1 \pm 1.0$ & 32.7 & $13: 02$ & $\begin{array}{l}\text { Hampton, } \\
\mathrm{NE}\end{array}$ \\
\hline $\begin{array}{l}1 \\
\text { (Arduino) }\end{array}$ & $\begin{array}{l}\text { 19 Aug } \\
(11: 45)\end{array}$ & $\begin{array}{l}\text { Grand } \\
\text { Island, } \\
\mathrm{NE}\end{array}$ & $20.8 \pm 1.2$ & & 32.7 & $13: 02$ & $\begin{array}{l}\text { Hampton, } \\
\text { NE }\end{array}$ \\
\hline $\begin{array}{l}2 \\
\text { (Arduino) }\end{array}$ & $\begin{array}{l}\text { 19 Aug } \\
(12: 30)\end{array}$ & $\begin{array}{l}\text { Grand } \\
\text { Island, } \\
\text { NE }\end{array}$ & $19.6 \pm 1.3$ & $19.2 \pm 1.3$ & 31.6 & $14: 07$ & $\begin{array}{l}\text { Hampton, } \\
\text { NE }\end{array}$ \\
\hline $\begin{array}{l}3 \\
\text { (Arduino) }\end{array}$ & $\begin{array}{l}20 \text { Aug } \\
(11: 29)\end{array}$ & $\begin{array}{l}\text { Aurora, } \\
\mathrm{NE}\end{array}$ & $21.1 \pm 1.1$ & & 31.8 & $12: 52$ & $\begin{array}{l}\text { Gresham, } \\
\text { NE }\end{array}$ \\
\hline $\begin{array}{l}4 \\
\text { (Arduino) }\end{array}$ & $\begin{array}{l}20 \text { Aug } \\
(12: 04)\end{array}$ & $\begin{array}{l}\text { Aurora, } \\
\mathrm{NE}\end{array}$ & $19.1 \pm 0.9$ & $17.5 \pm 1.1$ & 29.8 & $12: 04$ & $\begin{array}{l}\text { Hampton, } \\
\text { NE }\end{array}$ \\
\hline Average & & & $20.2 \pm 0.9$ & $18.3 \pm 1.0$ & & & \\
\hline
\end{tabular}

Table 1. Pre-eclipse RP maximum data

\begin{tabular}{|l|l|l|l|l|l|l|l|l|}
\hline $\begin{array}{l}\text { Flight } \\
\text { Number } \\
\text { (System) }\end{array}$ & $\begin{array}{l}\text { Date } \\
(\text { Launch } \\
\text { time })\end{array}$ & $\begin{array}{l}\text { Launch } \\
\text { Site }\end{array}$ & $\begin{array}{l}\text { Omnidirectional } \\
\text { RP maximum } \\
(\mathrm{km})\end{array}$ & $\begin{array}{l}\text { Vertical } \\
\text { Coincidence } \\
\text { RP } \\
\text { Maximum } \\
(\mathrm{km})\end{array}$ & $\begin{array}{l}\text { Burst } \\
\text { Altitude } \\
(\mathrm{km})\end{array}$ & $\begin{array}{l}\text { Time } \\
\text { at } \\
\text { Burst } \\
(\mathrm{CDT})\end{array}$ & $\begin{array}{l}\text { Altitude } \\
\text { at } \\
\text { Totality } \\
(\mathrm{km})\end{array}$ & $\begin{array}{l}\text { Recovery } \\
\text { Site }\end{array}$ \\
\hline $\begin{array}{l}5 \\
\text { (Stratostar) }\end{array}$ & $\begin{array}{l}21 \mathrm{Aug} \\
(11: 35)\end{array}$ & $\begin{array}{l}\text { Aurora, } \\
\text { NE }\end{array}$ & $21.1 \pm 1.3$ & $17.6 \pm 1.4$ & 30.1 & $12: 55$ & $\begin{array}{l}18 \\
\text { (descending) }\end{array}$ & $\begin{array}{l}\text { Garrison, } \\
\text { NE }\end{array}$ \\
\hline $\begin{array}{l}5 \\
\text { (Arduino) }\end{array}$ & $\begin{array}{l}21 \mathrm{Aug} \\
(11: 35)\end{array}$ & $\begin{array}{l}\text { Aurora, } \\
\text { NE }\end{array}$ & $20.5 \pm 1.2$ & & 30.1 & $12: 55$ & $\begin{array}{l}18 \\
\text { (descending) }\end{array}$ & $\begin{array}{l}\text { Garrison, } \\
\text { NE }\end{array}$ \\
\hline $\begin{array}{l}6 \\
\text { (Arduino) }\end{array}$ & $\begin{array}{l}21 \mathrm{Aug} \\
(12: 00)\end{array}$ & $\begin{array}{l}\text { Aurora, } \\
\text { NE }\end{array}$ & $20.6 \pm 1.1$ & $17.4 \pm 0.8$ & 31.0 & $13: 25$ & $\begin{array}{l}22 \\
\text { (ascending) }\end{array}$ & $\begin{array}{l}\text { Garrison, } \\
\text { NE }\end{array}$ \\
\hline $\begin{array}{l}6 \\
\text { (Arduino) })\end{array}$ & $\begin{array}{l}21 \mathrm{Aug} \\
(12: 00)\end{array}$ & $\begin{array}{l}\text { Aurora, } \\
\text { NE }\end{array}$ & $20.6 \pm 0.9$ & & 31.0 & $13: 25$ & $\begin{array}{l}22 \\
\text { (ascending) }\end{array}$ & $\begin{array}{l}\text { Garrison, } \\
\text { NE }\end{array}$ \\
\hline $\begin{array}{l}7 \\
\text { (Arduino) }\end{array}$ & $\begin{array}{l}21 \mathrm{Aug} \\
(12: 25)\end{array}$ & $\begin{array}{l}\text { Aurora, } \\
\text { NE }\end{array}$ & $19.3 \pm 1.6$ & $19.2 \pm 1.9$ & 31.5 & $13: 49$ & $\begin{array}{l}14 \\
\text { (ascending) }\end{array}$ & $\begin{array}{l}\text { Garrison, } \\
\text { NE }\end{array}$ \\
\hline Average & & & $20.4 \pm 0.8$ & $18.0 \pm 1.0$ & & & & \\
\hline
\end{tabular}

Table 2. Eclipse day RP maximum data 
All the flights were lifted by Howyee weather balloons $(1600 \mathrm{~g})$ with a nozzle lift of 18 pounds with payload stacks that varied from 11.25 pounds to 11.75 pounds. The payloads were instrumented with a combination of Stratostar, Arduino, Aware Electronics, and custom-made equipment. Temperature, pressure, humidity, GM counts, and GPS information were logged. Figure 1 provides an example of the arrangement of the instrumentation included in the payloads. The GPS information included latitude, longitude, altitude, and time. Aware Electronics RM-60 GM counters measured omnidirectional counts. For the vertical coincidence counts, two Aware Electronics RM-80 counters were stacked vertically. A support structure and a thin piece of steel were inserted between the two detectors. The steel was included to remove the effect of secondary electrons created in an ionizing event in only one detector. The RM-80s are pancake detectors with a radius of $2.75 \mathrm{~cm}$ and a separation of $6.0 \mathrm{~cm}$. When stacked, these detectors have a solid angle sensitivity of $1.65 \mathrm{sr}$. GM counts and the other data were recorded every 5 seconds.

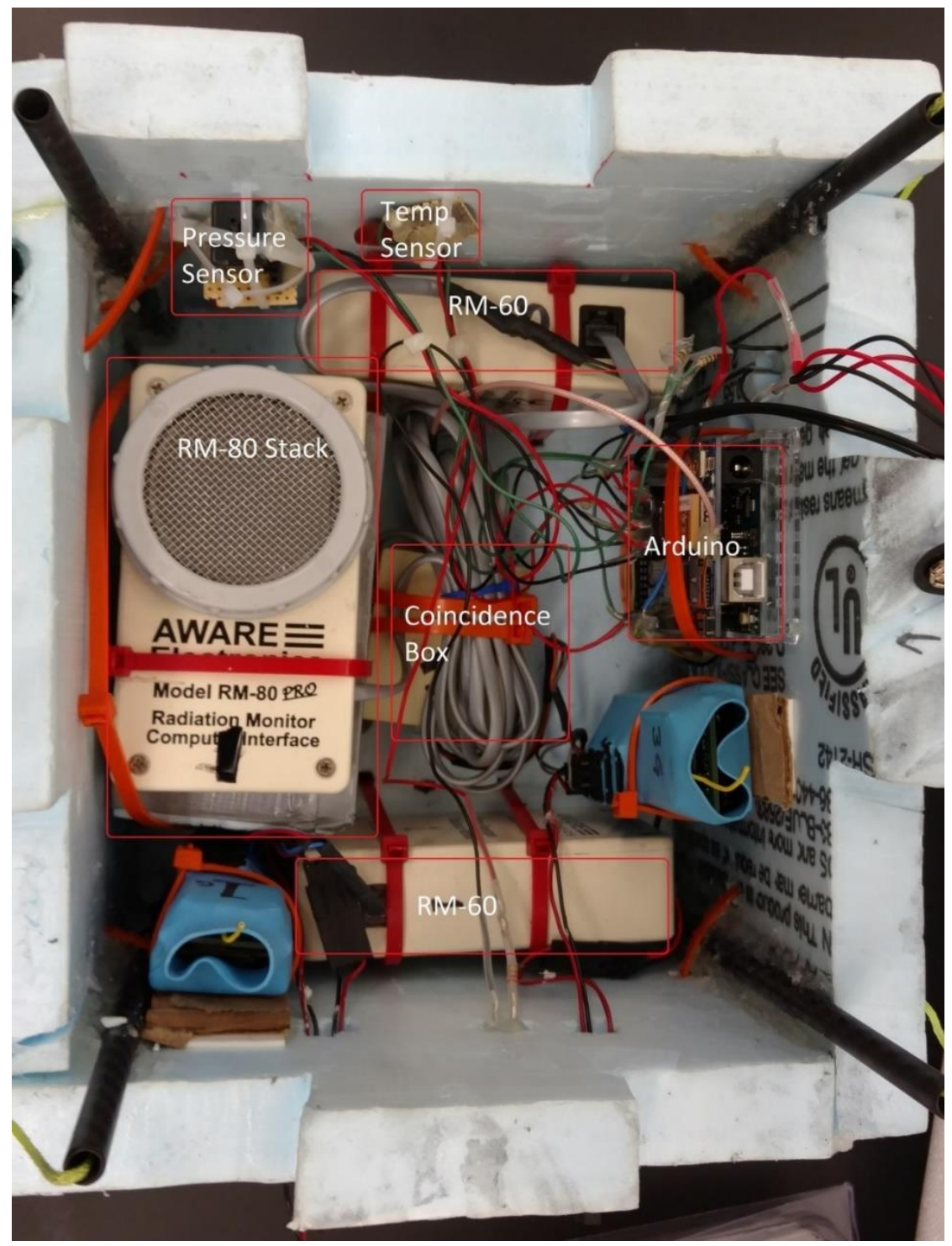

Fig. 1. The instrumentation of UMM payload \#1flown on Flight \#1 (19 August 2017) and Flight \#5 (21 August 2017) . It contains two RM-60 GMs for the detection of omnidirectional cosmic rays and two stacked RM-80 GMs for the detection of vertical cosmic ray coincidence counts. Temperature and pressure sensors are also included. 


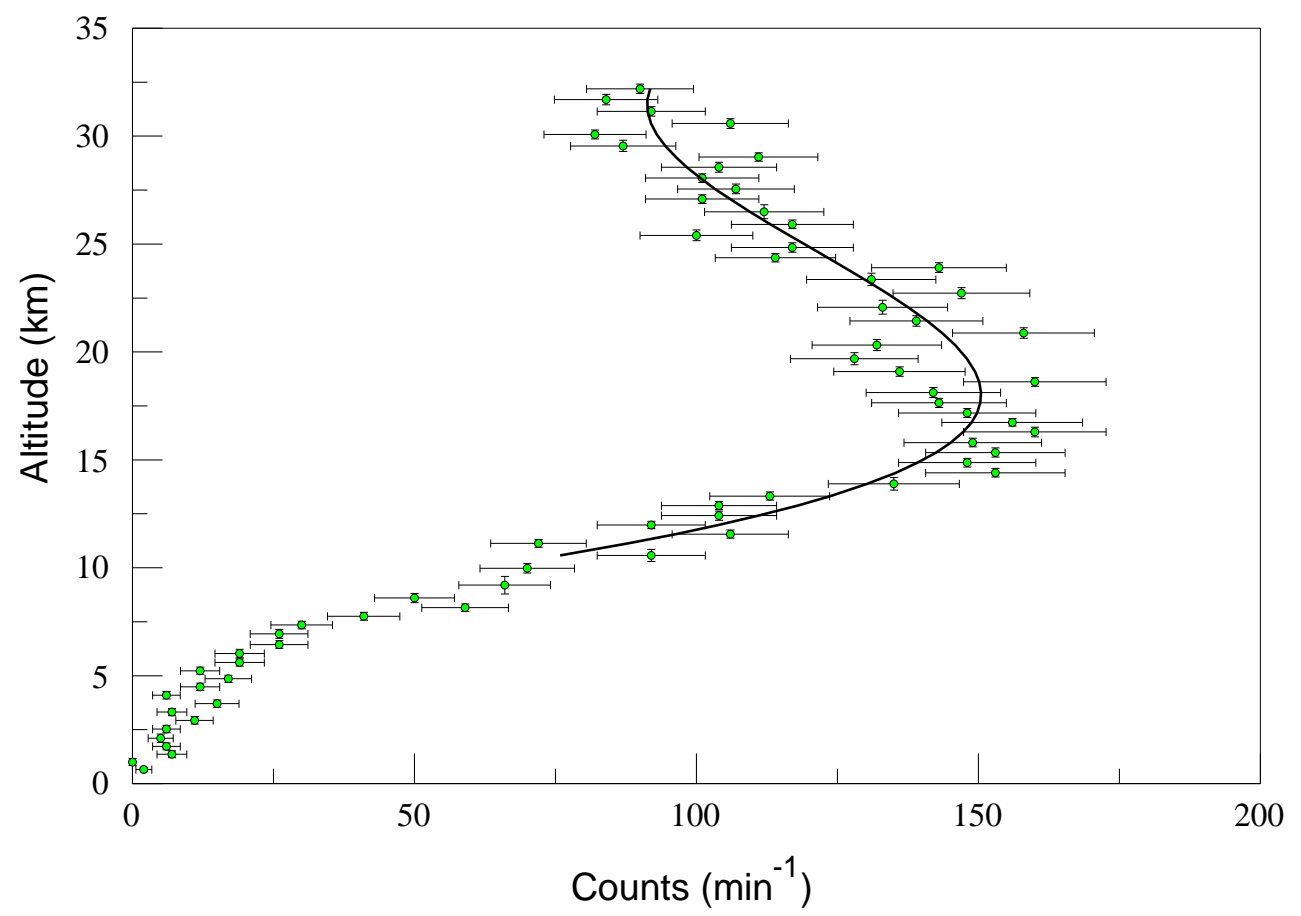

Fig.2. Altitude versus vertical coincidence counts from Flight \#1, pre-eclipse. RP maximum at $18.1 \mathrm{~km} \pm 1.0 \mathrm{~km}$.

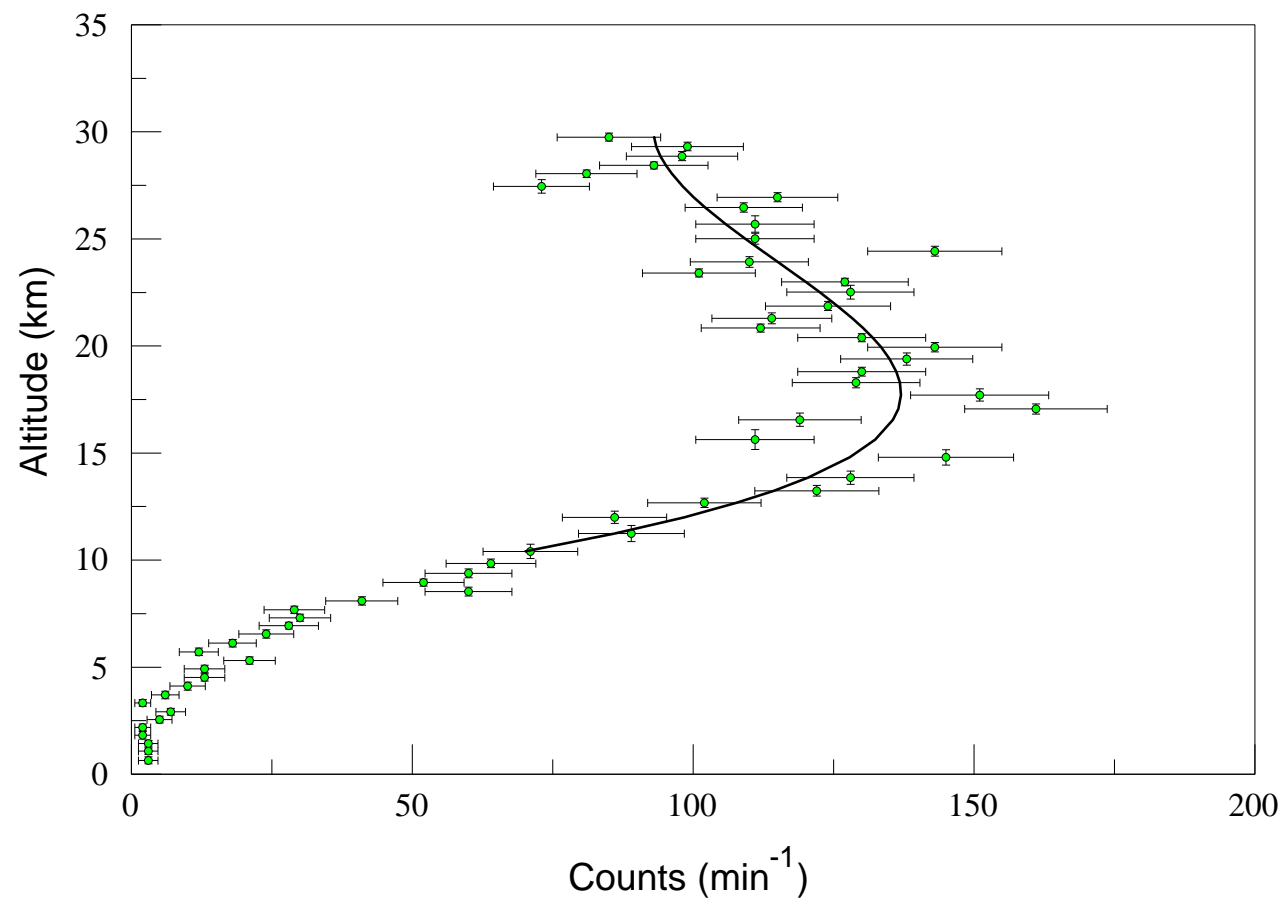

Fig. 3. Altitude versus vertical coincidence counts from Flight \#5, during the eclipse. RP maximum at $17.6 \mathrm{~km} \pm 1.4 \mathrm{~km}$. 


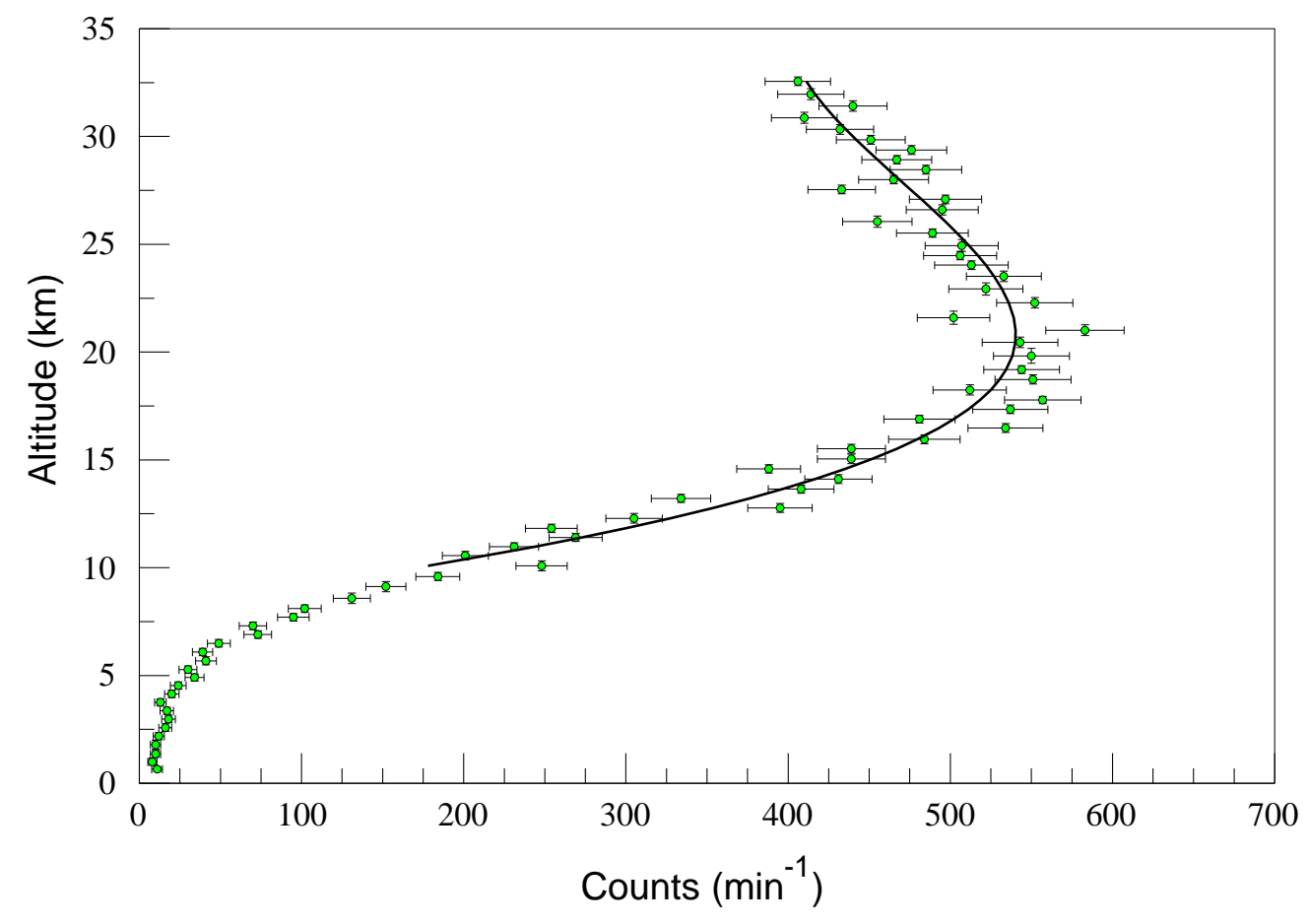

Fig. 4. Altitude versus omnidirectional counts from Flight \#1 (19 August 2017), pre-eclipse. RP maximum at $20.6 \mathrm{~km} \pm 1.2 \mathrm{~km}$.

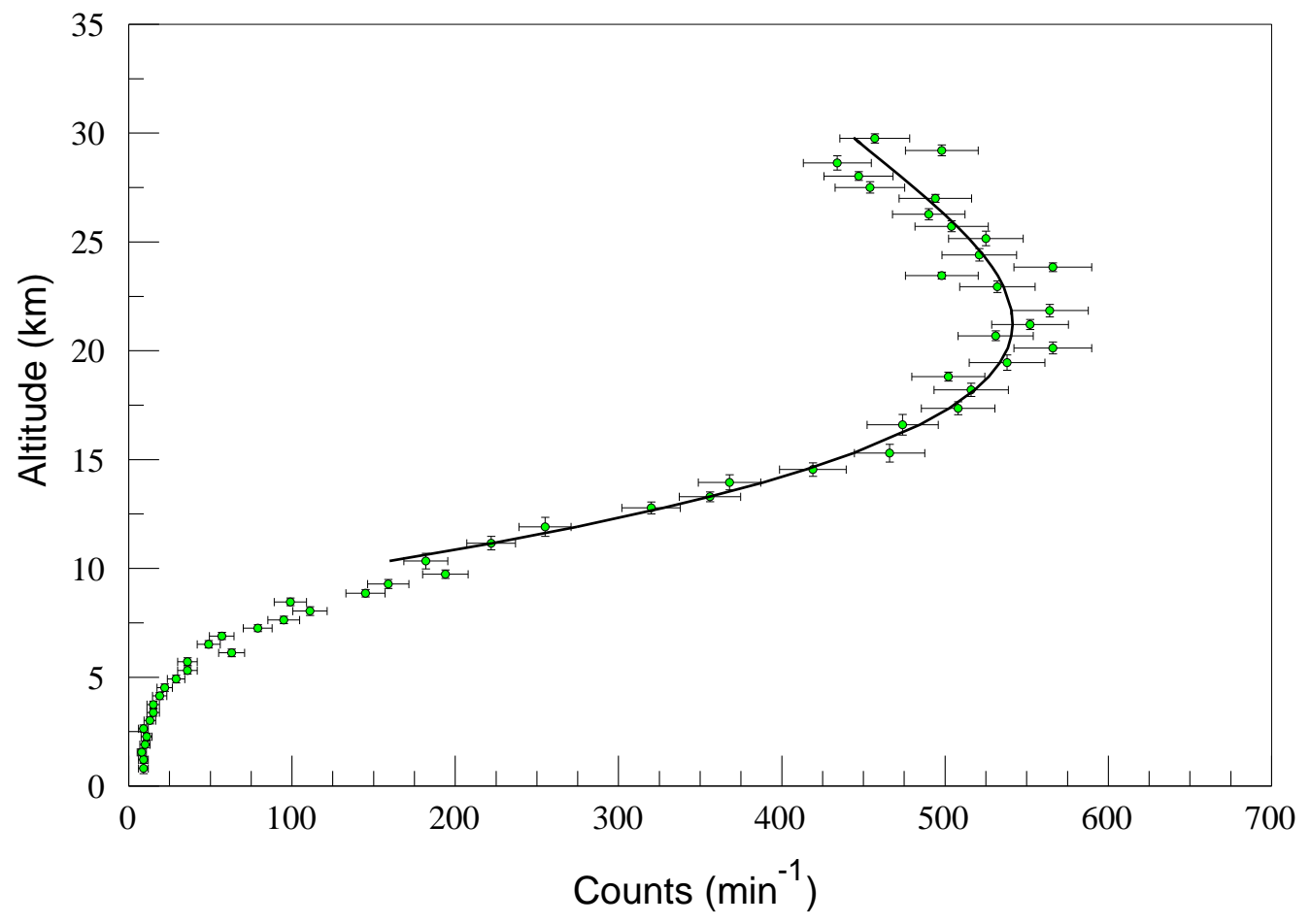

Fig. 5. Altitude versus omnidirectional counts from Flight \#5 (21 August 2017), during the eclipse. RP maximum at $21.1 \mathrm{~km} \pm 1.3 \mathrm{~km}$. 


\section{Analysis and Results}

To carry out the data analysis, five second measurements of GM counts during the ascent were accumulated into one minute sums. Only the ascent information was used due to the relatively uniform vertical velocities during the ascents. The one minute accumulations reduce the noise in the data and simplify the fitting process. In Figs. $2-5$ the error bars in altitude show the range of altitudes over which the five second counts were accumulated into one minute sums. The error bars in counts per minute indicate the uncertainty in the counts assuming Poisson statistics. Poisson statistics are generally used in such counting measurements. The RP maximum was then determined by fitting a third order polynomial to the counts per minute versus altitude data above $10,000 \mathrm{~m}$. Below 10,000 m the data have a different altitude dependence since few particles are being created and many particles are decaying. Third order polynomials were chosen by visually comparing second order polynomial and third order polynomial fits to the data. The third order polynomials, shown in the figures, provided a visually and statistically better fit. The uncertainties in the RP maxima were determined from the fitted altitudes of the maximum count rate plus and minus the standard error of the fit data. The fitting procedure and further examples of the fits have been presented by Taylor et al. [20]. Table 1 and Table 2 provide the values for the RP maxima and their uncertainties for the omnidirectional and vertical coincident counts on the days before the eclipse and the day of the eclipse. The eclipse achieved totality at 13:01 CDT and continued in totality for two minutes along the balloons' trajectories.

\section{Conclusions}

The omnidirectional and vertical coincidence RP maxima have been determined before and during the 21 August 2017 total solar eclipse. No changes in the RP maxima outside the range of the pre-eclipse measurements were observed. This result provides no evidence that the altitudes of the RP maxima were affected by the meteorological changes that occurred during the eclipse. It is not clear that the RP maxima is a direct measurement of the altitude of the interaction layer proposed to be at $16000 \mathrm{~m}$. The interaction layer could have changed altitude or, in a delayed effect, changed after the balloons had passed through that layer. It may take time for the stratospheric cooling that occurred during the eclipse to affect the temperature, density, and altitude of the interaction layer. Further work is required to understand the relationship between the RP maximum and the interaction layer altitude and the effect of a changing stratospheric temperature on the interaction layer.

Our observations indicate that the omnidirectional RP maximum is consistently at a higher altitude than the vertical coincidence RP maximum. Allkofer [3] and Grieder [21] both briefly discuss the combined zenith angle and altitude dependence of the cosmic ray intensity, but little observational work has been done. Further theoretical and experimental work are being planned to study and measure the zenith angle dependence of the RP maximum.

Cosmic ray measurements at the surface of the Earth are dominated by $\mu$ s with a cosine squared of the zenith angle dependence [3,21]. That is, cosmic rays near the vertical have a much higher intensity than those at larger zenith angles. So the vertical component of the high altitude cosmic rays may have a greater effect on surface measurements than the high altitude omnidirectional cosmic rays. Our measurements indicate that the vertical coincidence RP maximum occurs at a lower altitude than the omnidirectional RP maximum. The vertical coincidence RP maximum is therefore closer to the proposed interaction layer at $16,000 \mathrm{~m}$ and may be a better indicator of the altitude of the interaction layer. This possibility will be explored in future balloon flights.

\section{Acknowledgments}

This research would not have been possible without the support of the University of Minnesota, Morris, through Morris Academic Partnerships, UMM Faculty Research Enhancement Funds, and UMM student volunteers. The NASA Minnesota Space Grant Consortium also provided extensive support.

E. Agrimson and K. Smith thank the support of St. Catherine University administration and alumni for help in funding the Summer Scholars program which assisted us with student hours during the summer of 2017 and the St. Catherine University Academic Professional Development Committee faculty development funds for summer 2016 and 2017 research supplies assistance. We also wish to thank the Henry Luce Foundation as part of the Clare Booth Luce (CBL) program to enhance undergraduate research opportunities for women majoring in Physics, Mathematics and Chemistry. We received support from CBL during the academic year 2014-2015. We also wish to thank the Denny family for the Carol Easley Denny award which provided student hours and supplies for the academic year 2015-2016. We also wish to thank the assistant mentorship program, which funded student hours during the fall of 2017.

We are grateful to all the individuals and organizations that contributed to this research. 


\section{References}

[1] National Weather Service, Space Weather Prediction Center, URL: http://legacywww.swpc.noaa.gov/weekly/pdf/prf2191.pdf [retrieved 15 October 2017].

[2] Regener, E., "New Results in Cosmic Ray Measurements," Nature, Vol. 132, 1933, pp. 696 - 698.

[3] Allkofer, O.C., Introduction to Cosmic Radiation, Verlag Thiemig, Munich, 1975.

[4] Pomerantz, M.A., Cosmic Rays, Van Nostrand Reinhold Company, New York, 1971.

[5] Berkova, M., Belov, A., Eroshenko, E., and Yanke, V., "Temperature effect of muon component and practical questions of how to take into account in real time," Astrophys. Space Sci. Trans., 8, 2012, pp. 41-44.

[6] Savic, M., dragic, A., Veselinovic, N., Udovicic, V., Banjanac, R., Jokovic, D., and Maletic, D. "Effect of pressure and temperature corrections on muon flux variability at ground level and underground," XXV European Cosmic Ray Symposium, Turin, 2016.

[7] De Mendonca, R., Raulin, J., Escher, E., Makhmutov, and Fernandez, G., "Analysis of atmospheric pressure and temperature effects on cosmic ray measurements," Jour. Geophys. Res.:Space Physics, Vol. 118, 2013, pp. 14031409.

[8] Dorman, L.I., Cosmic Rays in the Earth's Atmosphere and Underground, Kluwer Academic Publishers, Dordrecht, 2004.

[9] Amsler, C. et al., “24. Cosmic Rays,” Physics Letters, Vol. B667, 2008, pp. 1 - 20.

[10] Zabori, B., Hirn, A., Deme, S., Apathy, I., and Pazmandi, T, "Characterization of Cosmic Rays and Direction Dependence in the Polar Region up to 88 km altitude," J. Space. Weather Space Clim., Vol. 6, 2016, pp. A12:1 - 7.

[11] Adams, A., Brauer, E., and Stroman, J. "A Small Geiger Counter Array," Proceedings of the $2^{N D}$ Annual Academic High Altitude Conference, Iowa State University, Ames, IA, USA, 2011.

[12] Bhattacharyya, A. et al., "Variations of $\gamma$-Ray and particle Fluxes at the Sea Level during the Total Solar Eclipse of 24 October, 1995," Astrophys. Space Science, Vol. 250, 1997, pp. 313 - 326.

[13] Chintalapudi, S. et al., "The $\gamma$ and X ray measurements during Total Solar Eclipse on October 24, 1995 at Diamond Harbour," Kodaikanal Obs. Bull., Vol. 13, 1997, pp. 225 - 234.

[14] Kandemir, G. et al., "Variations of Cosmic Ray Intensity During the Solar Eclipse August 11, 1999," ASP Conference Series, 205, Livingston and Ozguc eds. 2000.

[15] Nayak, P. et al., "A Study of the $\gamma$-Ray Flux during the Total Solar Eclipse of 1 August 2008 at Novosibirsk, Russia," Astroparticle Physics, Vol. 32, 2010, pp. 286 - 293.

[16] Bhattacharyya, A, Roy, A., Biswas, M., Guha, R., and Bhoumick, A., "Cosmic Ray Intensity and Surface Parameters during Solar Eclipse on 22 July 2009 at Kalyani in West Bengal," Current Science, Vol. 98, Num. 12, 2010, pp. 1609 - 1614.

[17] Mishra, R., Agarwal, R., Samson, I., and Daksh, S., "Characteristics of Cosmic Ray Intensity Variations on the Onset of Solar Eclipses at the Earth's Surface," 32nd International Cosmic Ray Conference, Beijing 2011.

[18] Bhaskar, A. et al., "A Study of Secondary Cosmic Ray Flux Variation during the Annular Eclipse of 15 January 2010 at Rameswaram, India," Astroparticle Physics, Vol. 35, 2011, pp. 223 - 229. 
[19] Devendra P., Jaaffrey, S., Talestra, K. Ravi, Y., and Sonia, A., "Experimental Study of Variation of Secondary Cosmic Gamma Ray Flux and energy during Partial Solar Eclipse of $4^{\text {th }}$ January 2011 at Udaipur, India," Res. J. Physical. Sci., Vol. 1, Num. 5, 2013, pp. 22 - 30.

[20] Taylor, L., McIntosh, G., Swanson, A., Agrimson, E. and Smith, K., "Data Processing and Curve Fitting of Counts Data," The Proceedings of the $8^{\text {th }}$ Annual Academic High Altitude Conference, University of Minnesota, Minneapolis, MN, USA, 2017.

[21] Grieder, P., Cosmic Rays at Earth, Elsevier, New York, Chap. 1, 2001. 